\title{
Bone Cells Dynamics during Peri-Implantitis: a Theoretical Analysis
}

\author{
Maria Helena Fernandes ${ }^{1}$, Pedro de Sousa Gomes ${ }^{1}$ \\ ${ }^{1}$ Faculty of Dental Medicine, University of Porto (FMDUP), Porto, Portugal.
}

\author{
Corresponding Author: \\ Maria Helena Fernandes \\ Faculty of Dental Medicine, University of Porto \\ Rua Dr. Manuel Pereira da Silva, 4200-393 Porto \\ Portugal \\ E-mail: mhfernandes@,fmd.up.pt
}

\begin{abstract}
Objectives: The present manuscript aims a detailed characterization of the bone cells dynamics during physiological bone remodelling and, subsequently, to address the cellular and molecular mechanisms that play a fundamental role in the immuneinflammatory-induced uncoupled bone remodelling observed in peri-implantitis.

Results: An intimate relationship between the immune system and bone is acknowledged to be determinant for bone tissue remodelling and integrity. Due to the close interaction of immune and bone cells, the two systems share a number of surface receptors, cytokines, signalling pathways and transcription factors that are involved in mutual regulatory mechanisms. This physiological equilibrium is disturbed in pathological conditions, as verified in peri-implantitis establishment and development. Activation of the innate and adaptive immune response, challenged by the local bacterial infection, induces the synthesis of high levels of a variety of pro- and anti-inflammatory cytokines that disturb the normal functioning of the bone cells, by uncoupling bone resorption and formation, ending up with a net alveolar bone loss and subsequent implant failure. Most data points to an immune-inflammatory induced osteoclast differentiation and function, as the major underlying mechanism to the uncoupled bone resorption to bone formation. Further, the disturbed functioning of osteoblasts, reflected by the possible expression of a fibro-osteoblastic phenotype, may also play a role.

Conclusions: Alveolar bone loss is a hallmark of peri-implantitis. A great deal of data is still needed on the cellular and humoral crosstalk in the context of an integrated view of the osteoimmunologic interplay occurring in the peri-implantitis environment subjacent to the bone loss outcome.
\end{abstract}

Keywords: alveolar bone loss; cellular immune response; humoral immune response; osteoblasts; osteoclasts; peri-implantitis.

Accepted for publication: 8 September 2016

To cite this article:

Fernandes MH, Gomes PS.

Bone Cells Dynamics during Peri-Implantitis: a Theoretical Analysis

J Oral Maxillofac Res 2016;7(3):e6

URL: http://www.ejomr.org/JOMR/archives/2016/3/e6/v7n3e6.pdf

doi: $10.5037 /$ jomr.2016.7306 


\section{INTRODUCTION}

Bone homeostasis is set up on a continuous renewal in response to mechanical, nutritional and local and systemic factors. This is accomplished by a highly regulated bone remodelling process, performed by the concerted actions of the bone forming osteoblasts, the bone resorbing osteoclasts and the bone matrix sensing osteocytes. Additionally, an intimate interaction between the immune system and bone is acknowledged to be determinant in bone integrity.

In peri-implantitis, the local immune-inflammatory process is associated with a disturbed bone remodelling. Induced osteoclastogenesis appears a major determinant in the uncoupled bone resorption to bone formation, ending in the loss of the supporting alveolar bone and implant failure. Basic knowledge on the cellular and humoral osteo-immunologic interplay in the peri-implantitis environment is essential to understand the underlying mechanisms leading to bone loss.

In this context, we first address the bone cells dynamics during physiological bone remodelling and, after, the cellular and molecular mechanisms that play a role in the immune-inflammatory induced uncoupled bone remodelling observed in peri-implantitis.

\section{BONE TISSUE}

Bone is a connective tissue composed of approximately $90 \%$ calcified extracellular matrix and $10 \%$ cells. The organic component of the matrix, $\sim 30 \%$, includes primarily collagen type I $(\sim 88 \%)$, non-collagenous proteins $(\sim 10 \%)$, and lipids and glycosaminoglicans as the remaining components [1]. This matrix is mineralized by the presence of calcium phosphate, in the form of hydroxyapatite $\left(\mathrm{Ca}_{3}\left[\mathrm{PO}_{4}\right]_{2} \cdot \mathrm{Ca}[\mathrm{OH}]_{2}\right)$, which accounts for $\sim 60 \%$ of the matrix [1]. The inorganic and organic phases of the matrix give bone its compressive and tensile strength, respectively. Quiescent bone surfaces are covered by a monolayer of bone-lining cells, while the bone matrix contains a well-organized network of osteocytes. The bone resorbing osteoclasts and the bone-forming osteoblasts are found in the active remodelling sites [1].

Primary bone function, linked to its mechanical properties, is to provide rigidity and shape, protection and support for body structures and assist in locomotion. Additionally, it is the major store of calcium and phosphate. As bone contains the marrow, it harbours the hematopoietic stem cells (HSCs), from which blood and immune cells are derived. Also, bone is now considered as an endocrine organ, contributing to the regulation of many tissues and organs [2]. It is a source of a variety of bioactive molecules involved in local and systemic metabolic activities, as calcium and phosphate homeostasis, kidney function and energy metabolism $[\underline{2}, \underline{3}]$.

Histologically, bone presents itself as cortical and trabecular. Cortical bone, up to $80 \%$ of the skeleton, is heavy mineralized and forms the outer layer of bones. It has a dense and ordered structure, being composed of concentric layers of bone matrix surrounding the Haversian canal [4]. Trabecular bone fills the inner parts of the bones. It is lighter and has an irregular structure containing a network of interconnecting plates and bars, the trabeculae, imbibed in marrow [4]. Together, the mineral and the organic content, and the structural organization in cortical and trabecular, give bone its performance in resisting torque, compression and shear stress [4].

Bone is a very dynamic tissue continuously undergoing modelling and remodelling processes. Bone modelling assists in bone shape and size changes to allow harmonic growth and adaptation to mechanical loading. It is a bone resorption and bone formation unbalanced process, in favour of the later, occurring in diverse sites to properly shape the bone [5]. Bone remodelling is a highly concerted and coupled process, in which resorption of old or damaged bone is replaced by the same amount of new bone, allowing the tissues to maintain homeostasis and integrity $[\underline{5}, \underline{6}]$. Imbalance in bone remodelling, observed with aging and in some local and systemic pathological conditions, leads to the development of bone metabolic disorders.

Figure 1 shows a simplified representation of the bone cells and their differentiation pathways.

Familiarity to the basic biology of the cells involved in the bone remodelling is helpful to understand the molecular and cellular mechanisms underlying the pathogenesis of bone disorders, namely the bone loss associated to peri-implantitis. Following, is a more detailed description of the biology of the bone cells and bone remodelling in physiological conditions.

\section{BONE CELLS: DIFFERENTIATION, MATU- RATION AND COUPLING \\ Osteoblasts and bone formation}

Osteoblasts are the cells responsible for the production of the bone extracellular matrix and its mineralization. They originate from pluripotent mesenchymal stem cells (MSCs), recruited from 
the neighbouring microenvironment, which can also differentiate into other mesenchymal cell lineages such as chondrocytes, myoblasts and adipocytes, depending on the activated signalling transcription pathways.

Osteoblastic differentiation is regulated by a complex spatiotemporal endocrine, paracrine and autocrine interactions, involving a variety of hormones and a large number of growth factors and cytokines. This process proceeds along a linear sequence moving from osteoprogenitors, pre-osteoblasts to fully mature osteoblasts (Figure 1). In this pathway, in vitro and in vivo studies suggest a temporal sequence of events involving active cell proliferation (that is accompanied by the synthesis of the organic matrix, the osteoid), matrix maturation and organization (during which cell growth does not occur), and matrix mineralization. According to this model, there is a reciprocal and functionally coupled relationship between proliferation and differentiation that must be maintained tightly coupled and regulated to support normal bone formation [7].

Osteoblast lineage cells express receptors for a wide variety of systemic and local factors, having a key role in the bone microenvironment events. Within this regulatory role, they produce a diversity of molecules in response to stimuli coming from physiological needs related to bone remodelling and homeostasis, as well as other bone functions. Osteoblasts' phenotype is also highly sensitive to local modifications, as those verified within the inflammatory response, intimately associated to the presence of a plentiful of cytokines due to the immune-inflammatory infiltrate. These will affect osteoblast functioning, including the expression profile of a variety of growth factors and cytokines that modulate the behaviour of the cells present in bone environment [1].

Within its paracrine activity, stromal cells/osteoblast cells are deeply involved in the regulation of osteoclast differentiation and activity, mediated by the synthesis of monocyte/macrophage colonystimulating factor (M-CSF), and receptor activator of nuclear factor $\kappa \mathrm{B}$ ligand (RANKL), two osteoclastogenic factors, and osteoprotegerin (OPG), an inhibitor of osteoclastogenesis. This modulation occurs both in physiological bone remodelling but also in pathological conditions affecting this process, as it will be discussed later [1] .

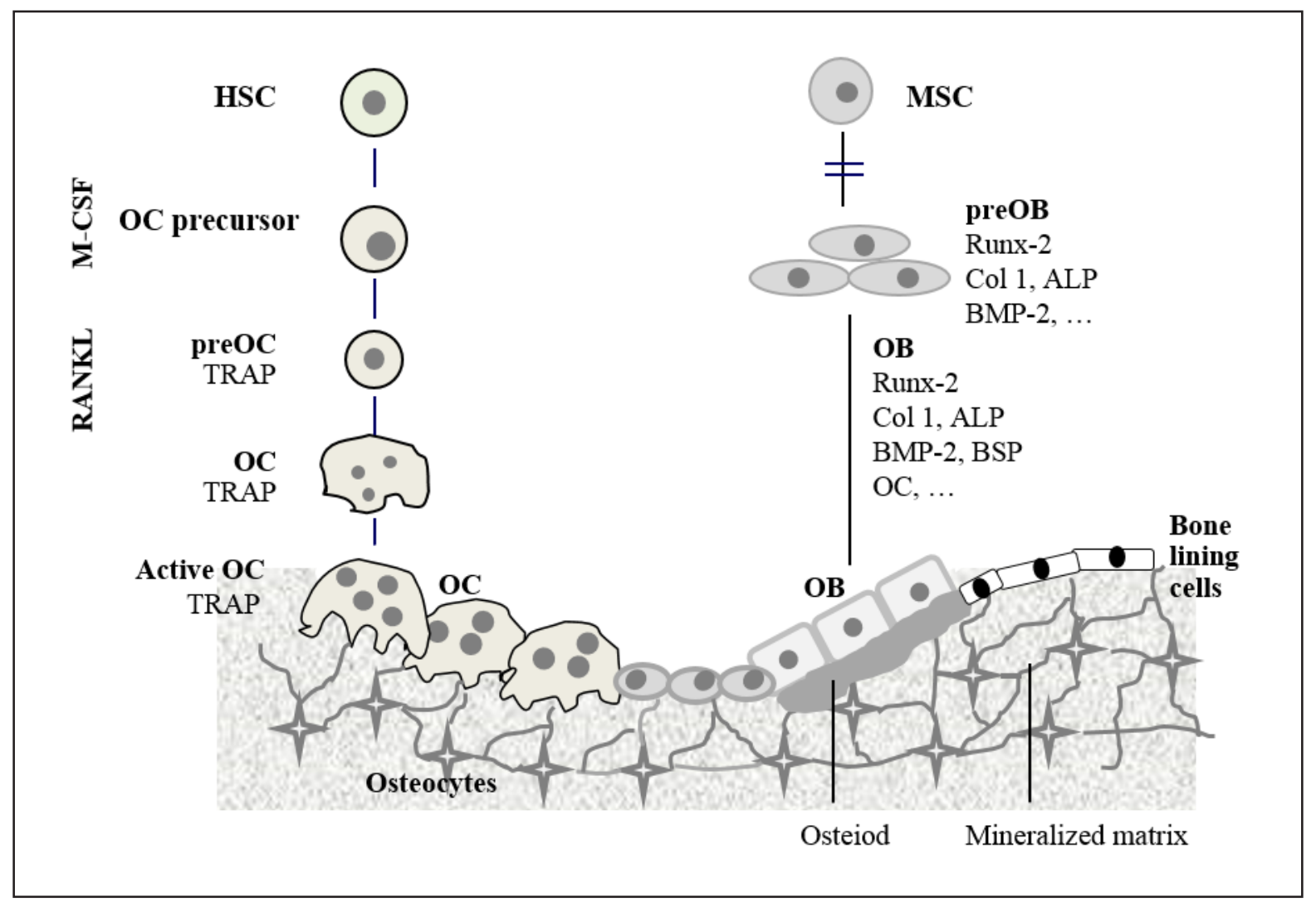

Figure 1. Simplified representation of the bone cells and their differentiation pathways, in a bone remodelling site. $\mathrm{HSC}=$ hematopoietic stem cell; $\mathrm{MCS}=$ mesenchymal stem cell; $\mathrm{OC}=$ osteoclast; $\mathrm{OB}=$ osteoblast.

Active osteoclasts are characterized by a ruffled membrane, actin ring organization, expression of vitronectin receptors and cathepsin $\mathrm{K}$ (CATK), and are active on the bone resorption process. Active osteoblasts express characteristic osteogenic markers, being responsible for the osteoid synthesis and its subsequent mineralization. The intense cellular crosstalk develops within the frame of endocrine, paracrine and autocrine regulation. 


\section{The TGF- $\beta$ /BMP and Wnt/ $\beta$-catenin Osteoblast signalling pathways}

Two pathways have a key role in the osteoblast differentiation sequence - bone morphogenetic protein (BMP)/transforming growth factor- $\beta$ (TGF- $\beta$ ) and wingless-type MMTV integration site (Wnt)/ $\beta$-catenin signalling, as they are involved in the vast majority of cellular processes that lead to bone formation, i.e. osteoblast commitment, proliferation and differentiation $[\underline{1}, \underline{8}, \underline{9}, \underline{10}]$.

BMPs form the largest group of TGF- $\beta$ superfamily, and are so named for their osteoinductive properties. The TGF- $\beta / \mathrm{BMP}$ signal is mediated by membrane heterodimeric receptors and a family of intracellular receptor ligands, the Smad proteins that move into the nucleus and act as transcriptional regulators of several osteoblastic genes. Of note, BMP-2 and BMP7 induce the expression of Runt-related transcription factor 2 (Runx-2) and Osterix, the two critical transcription factors in osteoblast differentiation $[\underline{1}, \underline{8}]$. Wnts are cysteine-rich glycoproteins involved in controlling cell proliferation, cell fate specification, gene expression, and cell survival through the activation of diverse transcription factors. The Wnt/ $\beta$-catenin signalling (canonical Wnt pathway) has a major role in many stages of osteoblast lineage development and maturation [11]. Wnt binding with a membrane co-receptor complex involving lowdensity lipoprotein receptor-related protein 5 (LRP5) or LRP6, and one of the frizzled family member (Fz), leads to the release and activation of $\beta$-catenin in the cytoplasm, which translocate into the nucleus to modulate gene transcription of osteoblastic-specific genes, including Runx-2 []]. Wnt/ $\beta$-catenin pathway also contributes to osteoblasts and osteocytes survival []. In addition, the $\mathrm{Wnt} / \beta$-catenin signalling also plays a role in regulating the expression of the gene for OPG [12]. Wnt signalling is tightly regulated by various secreted antagonists. Among them, sclerostin, produced by the osteocytes, antagonizes the activity of LRP5/6 receptors, depressing bone formation.

\section{The transcription factors Runx-2 and Osterix}

Runx-2 is the key transcription factor in nuclear microenvironment responsible for the commitment of pluripotent MSCs into the osteoblast cell lineage, suppressing their differentiation into adipocytes and chondrocytes [1]. It is the master regulator for the expression of downstream key genes, as collagen type I, alkaline phosphatase, osteopontin, bone sialoprotein and osteocalcin, at an early stage of osteoblastic differentiation $[\underline{8}, \underline{13}]$. Its action sustains a supply of a pre-osteoblastic population. Runx-2 expression is downregulated in the late stage of the osteoblast maturation when mature osteoblasts form bone [13]. A variety of proteins interact with Runx-2 and modulate its activity, with enhancing or inhibiting effects, which has direct consequences in the osteoblast differentiation and bone formation [8].

Runx-2 has also a role in the regulation of the expression of Osterix, a later key transcription factor for osteoblastic differentiation []]. Osterix is the second transcription factor that is essential for the final stages of osteoblast differentiation, abolishing the potential of pre-osteoblasts for differentiating into chondrocytes $[1, \underline{8}]$. It is involved in collagen type I and osteocalcin gene activation []]. Also, Osterix is a downstream regulator for Runx-2 activity [ $\underline{8}]$.

\section{The process of bone formation}

Mature osteoblasts are basophilic, mononuclear and polygonal cells responsible for the synthesis of the organic bone matrix and its mineralization. They exhibit the typical features of a protein producing cell, i.e. well-developed rough endoplasmic reticulum, prominent Golgi complex and chromatic nucleus with large nucleolus. The plasma membrane of osteoblasts is particularly rich in the enzyme alkaline phosphatase, which is a characteristic osteoblastic marker.

Osteoblasts form tight junctions with adjacent cells, and groups of 100 - 400 osteoblasts per bone-forming site produce a highly organized organic matrix - the osteoid.

The organic matrix is a complex mixture of a variety of proteins. It is composed mainly by collagen type I $(\sim 88 \%)$, glycoproteins (e.g., fibronectin, osteonectin, osteopontin and bone sialoprotein), $\gamma$-carboxyglutamic acid containing proteins (e.g., osteocalcin and matrix gla-protein), enzymes (e.g., alkaline phosphatase, collagenases, proteinases), proteoglycans (e.g., biglycan, decorin, hyaluronan), proteolipids and a number of growth factors (e.g., fibroblastic growth factors (FGFs), insulin-like growth factors (IGFs), TGF- $\beta$ s, BMPs) $[1,4]$. Matrix proteins are secreted in a certain and specific order during the differentiation process. For instance, alkaline phosphatase is expressed at least as early as the preosteoblast stage, while osteocalcin is highly expressed in mature osteoblasts, being considered, respectively, early and later osteoblastic markers. During the synthesizing activity, secreted biomolecules are incorporated in the osteoid but they also disseminate into the local microenvironment, and may enter local blood vessels appearing in the systemic circulation. 
Some of them attain high serum levels, such as alkaline phosphatase and osteocalcin, and can be used as indicators of the bone formation activities. Either being present in the surrounding environment or integrating the matrix, these proteins have important autocrine and paracrine functions, modulating the behaviour of the bone cells, being involved in cell-matrix interactions, controlling the matrix mineralization, regulating the bone turnover, and also influencing other cells in the marrow adjacent to bone remodelling sites $[\underline{1}, \underline{4}]$.

The organic matrix begins to mineralize after about a three weeks-time lag, with the deposition of highly substituted hydroxyapatite. Mineralization initiates in small vesicles that are formed from the cytoplasmic membrane of the osteoblast by a budding process. The membrane vesicles have a high activity of alkaline phosphatase that has a major role in the initiation of the process. This enzyme hydrolyses organic phosphate compounds providing appropriate concentrations of phosphate ions that concentrate near the membrane. The vesicles also contain proteins and phospholipids with calcium-binding ability, allowing the localized accumulation of calcium and phosphate ions. Once the levels of these ions overcome the point of solubility, deposition of calcium phosphate occurs within the vesicles. Upon filling the vesicles, inorganic crystals contact with the extra-vesicular space, which, in normal conditions, is rich in calcium and phosphate ions. During the extravesicular mineralization, crystals of hydroxyapatite fill the inter-collagen fibrils spaces of the osteoid and, upon the formation of stable mineral "critical nucleus", crystal growth becomes a faster physic-chemical driven process $[\underline{1}, \underline{4}, \underline{8}]$.

The half-life of the osteoblast is approximately three months and they have three destinations, namely apoptosis, become lining cells or being entrapped in the matrix, in lacunar spaces, converted into osteocytes $[\underline{1}, \underline{4}]$.

\section{Osteoclasts and bone resorption}

Osteoclasts comprise $1-2 \%$ of bone cells, and are specialized and motile multinucleated cells that are in charge of resorbing the bone matrix. They originate from hematopoietic myeloid lineage precursors that also give rise to monocytes, macrophages and dendritic cells. The differentiation of the mononuclear osteoclast precursors to active osteoclasts is regulated by a variety of systemic and local factors and complex intracellular signalling pathways $[\underline{1}, \underline{14}]$.

Osteoclast precursor differentiation in the marrow is induced directly by a variety of factors, including several key cytokines. Osteoclast precursors are also present in the blood, as post-mitotic cells, from where they are recruited to remodelling sites in bone and exposed to factors that stimulate their further differentiation in osteoclasts [14]. Two cytokines are essential in osteoclastogenesis. Initially, M-CSF, acting on specific membrane receptors (c-fms), is needed for the proliferation and survival of osteoclast progenitors. Following, the expression of the receptor activator of nuclear factor $\mathrm{\kappa B}$ (RANK), a homotrimeric trans-membrane protein member of the TNF-receptor superfamily, characterizes the population that is committed to differentiate into osteoclasts. Upon the binding of this receptor to its ligand, RANKL, the precursor cells initiate a maturation process, involving the fusion of the mononuclear cells to form multinucleated and polarized cells, able to activate their resorptive mechanisms (Figure 1). On activation, RANK interacts with the adapter protein TNF receptor associated factor 6 , which acts downstream to activate several signalling molecules, namely nuclear factor kappa beta and, finally, nuclear factor of activated T-cells 1 (NFATc1), the transcription factor critical for osteoclastogenesis; it translocate to the nucleus and promotes the expression of osteoclast-specific genes, such as tartrate-resistant acid phosphatase (TRAP), $\beta 3$ integrins, calcitonin receptors and cathepsin $\mathrm{K}[\underline{1}, \underline{14}]$. RANKL/RANK signaling also stimulates the capacity of osteoclasts to resorb bone and decreases osteoclasts apoptosis [14].

RANKL/RANK interaction also triggers reactive oxygen species production, such as superoxide anions, hydroxyl radicals and $\mathrm{H}_{2} \mathrm{O}_{2}$, which appear to act as key second messengers during osteoclastogenesis. They have been associated with many cellular responses, appearing to have a particular relevant role in metabolic bone diseases [15].

Co-stimulatory mechanisms mediated by the osteoclast membrane immunoreceptors osteoclastassociated receptor (OSCAR) and triggering receptor expressed on myeloid cells 2 (TREM2) seem also to be important for osteoclastogenesis. These receptors act through adaptor molecules that unleash certain intracellular signaling, also ending up with the activation of the master osteoclastogenesis transcription factor NFATc1 [1].

\section{The process of bone resorption}

Adhesion of multinucleated osteoclasts to the bone matrix is needed for bone resorption. Recognition of the bone matrix to be resorbed occurs mainly through the binding of the osteoclast membrane receptors, 
specially $\beta_{3}$ integrins, to recognition sites (the ArgGly-Asp, the RGD sequence) on the bone matrix proteins, namely osteopontin, bone sialoprotein II and collagen type I. Activated integrins recruit an intricate array of adhesion and regulatory proteins leading to the formation of an actin-rich ring facing the bone, the sealing zone, defining the area to be resorbed $[1,16]$. Osteoclasts are highly polarized cells, in order to optimize the resorption process. Inside the sealing zone, the re-organization of the cytoplasm allows the formation of a ruffled border membrane that greatly increases the surface area in contact with the matrix; additionally, polarized trafficking of endosomes and lysosomes to the ruffled border also occurs.

The resorption of the bone matrix is accomplished in two phases, i.e. dissolution of the mineral content, followed by the degradation of the organic components, achieved by the acidification of the lacuna and the activity of proteases, respectively. The resorption lacuna is a highly acidic microenvironment. This is attained by the combined actions of multi-subunit vacuolar ATPases and chloride channels, in the ruffled border, that, respectively, pump protons and chloride ions into the lacuna. Hydrochloric acid is formed and dissolves the hydroxyapatite mineral phase, making the organic matrix available for proteolytic degradation by endosomal metalloproteinases (especially matrix metalloproteinase-9 (MMP-9) and lysosomal proteinases (especially cathepsin K) $[\underline{4}, \underline{14}]$. Digested matrix proteins, including fragments of type I collagen, are taken up by endocytosis through the ruffled border, transported across the cytoplasm, and released by exocytosis into the extracellular space, a process named transcytosis [14]. Cytoplasmic vesicles containing the specific enzyme TRAP fuse with the transcytotic vesicles to destroy the endocytosed material. Some of these molecules are known to play a role in the regulation of cell behaviour in the bone microenvironment cells. They also diffuse to the bloodstream and can be detected in serum and urine. Some of them, namely the collagen fragments $\mathrm{N}$-telopeptide of type I procollagen and C-telopeptide of type I collagen may function as a measure of bone resorption.

Osteoclasts are highly motile cells that move across the bone surface and resorb relatively large areas of bone. They have an average half-life of two weeks and die by apoptotic processes regulated by paracrine mechanisms $[14,16]$.

\section{Osteocytes and bone sensing system}

Osteocytes are found embedded within the bone matrix in small lacunae, and are the most abundant (90-95\%) and the most long lived bone cells. The osteocytes have an elevated number of cytoplasm processes, which run inside lacunar canaliculi that form an elaborate communication system, permeating the all bone matrix $[1,4]$.

The osteocyte differentiation (osteocytogenesis), with the formation of cytoplasm processes, appears to be dependent on the cleavage of collagen type I, the main protein matrix, fibrin, fibronectin and other matrix proteins by certain proteinases (e.g., membrane type I-matrix metalloproteinase, a membraneanchored metalloproteinase). Once the osteoblast begins to become an osteocyte, increased expression of a number of matrix proteins is observed, among them dentin matrix acidic phosphoprotein 1 (DMP1), FGF23 and sclerostin. DMP1 has an important role in osteocyte maturation, as evident by the high level of expression particularly in the cytoplasm processes and increased expression in response to mechanical loading [1]. FGF23 is involved in phosphate and vitamin D metabolism. Sclerostin is a soluble molecule that decreases bone formation [1] .

\section{The sensing system}

The structural design of the osteocytes' network within the extracellular matrix allows for a tremendous cell-bone surface contact area, an extensive communication system among neighbouring osteocytes, cells in the bone surface and blood vessels, and also the diffusion of small molecules that participate in a variety signalling pathways. It is viewed as a mechanosensory and communication system ideally suited to detect mechanical changes, deep bone lesions and respond to systemic hormonal stimuli, driving cellular activity to ensure bone homeostatic and adaptive responses [1].

The signal transduction, i.e. conversion of the mechanical/biochemical stimuli to appropriate adaptive cellular responses, involves a complex modulation by several membrane proteins, intracellular mediators and signalling molecules [1]. Mechanical stress and other stimuli result in very small deformations (strains) leading to changes in the interstitial fluid flow, through the canaliculi network that induces streaming potentials and fluid shear stress. Transduction of these signals encompass a variety of cell surface adhesion proteins, as integrins, connexins and stretch-activated ion channels that, through intracellular signal mediators (e.g., inositol trisphosphate, intracellular calcium, cyclic adenosine monophosphate, mitogen-activated protein kinase [MAPK]), lead to the production of 
bioactive molecules such as prostaglandins, adenosine triphosphate, nitric oxide, FGF23 and DMP1, that diffuse through the bone matrix and modulate the activity of surface bone cells [1].

Osteocytes produce two key molecules to regulate the behavior of the osteoblast and osteoclast lineage cells

- RANKL and sclerostin. Osteocytes appear to be a major source of RANKL, driving osteoclast formation and activation. On the other hand, sclerostin has a negative effect in osteoblast differentiation [1, 17] .

\section{BONE REMODELLING CYCLE}

Bone remodelling occurs in specific specialized vascularized entities, the bone remodelling compartments, which provide the structural basis for coupling and regulation of cellular activity. Bone remodelling requires a functional cohort of cells, the basic multicellular unit (BMU), which involves the coordinated action of the major types of bone cells, i.e. lining cells, osteocytes, osteoclasts and osteoblasts, and endothelial cells to support angiogenesis [1, $\underline{4}]$. It comprises four major distinct but overlapping phases - activation, resorption, reversal and formation.

In a quiescent state, the bone surface is covered by a monolayer of bone lining cells, which contribute to the regulation of bone fluid composition and circulation, exchange with extracellular fluids and ion homeostasis [1,4]. They communicate with the osteoblastic and osteoclastic progenitors in the marrow, having a role in the regulation of new bone formation or resorption. These cells belong to the osteoblast lineage, as they are remnants of previous osteoblasts that, at the end of the formation phase, reduce their cytoplasm and organelles, becoming quiescent.

Activation is the initiating event that converts a resting bone surface into a remodelling surface. The signal for induction of remodelling, and the choice of the site, appears to be determined by the osteocytes in the matrix, acting as a sensing system, detecting mechanical and biochemical stimuli (e.g., microdamage, ischemic events) [17, 18]. The transduction of these signals leads to the appropriate cellular activity at the bone surface.

As a result, retraction of the lining cells occurs to uncover the bone surface to be remodelled. Osteoclast precursors are recruited and, following a differentiation process, active osteoclasts attach to the bone matrix via integrins and other celladhesion receptors, and resorb a portion of the underlying matrix, forming a resorption lacuna.
This is a relatively rapid process estimated to be completed in few days. The resorbing phase ends with the activation of apoptotic pathways and consequent osteoclast apoptosis in the resorption lacuna, liberating the remodelling area $[1,4]$. The factors that regulate the cessation of the resorption phase in a particular site are not clearly understood and may be related with several factors, such an increase in local concentration of calcium and phosphate (resulting from the degradation of the bone matrix), release of factors from the degraded matrix, signals from the osteocytes, among others $[\underline{14}, \underline{16}]$.

The appearance of a heterogeneous population of macrophage-like mononuclear cells in the resorption lacunae marks the beginning of the reversal phase, lasting 7 - 14 days. The lacuna is levelled by the removal of the matrix debris left behind during the osteoclast activity, and a cement line substance enriched in proteoglycans appears, demarcating the edge at which osteoclasts stopped their activity. The reversal phase is a critical period between bone resorption and bone formation, and appears to be important in the coupling of the two processes. Reversal cells may release factors important for the following bone formation phase, and/or might contribute to the formation of the cement line that may play a role in guiding osteoblasts during the bone formation phase [1].

Subsequently, osteoblast precursor cells are recruited to the resorption lacuna and differentiate into osteoblasts. The mechanisms responsible for these events are not completely known. There are many factors with osteoblast anabolic effects released from the bone matrix during the resorption phase, i.e. TGF- $\beta$, BMPs, PDGF, FGFs, IGFs. Also, there is evidence that osteoclasts express factors that stimulate osteoblastic cell behaviour, such as sphingosine 1-phosphate $[4,19,20]$. The functional osteoblasts lay down a collagenous organic matrix, the osteoid, that later becomes mineralized by the deposition of hydroxyapatite. This is a slow phase, taking three to four months. During the formation phase, the more mature osteoblasts are entrapped in the organic matrix, becoming osteocytes. At the end of the formation phase, the resorption lacuna is completely filled with new bone, without any changes in the total bone amount. The mechanisms involved in the termination of this phase are unclear, but the major signal is very likely released by the osteocytes embedded in the mineralized matrix. Osteocytes secrete sclerostin that prevents the activation of the Wnt signalling, an important osteoblast inducer $[19,21]$.

The adult skeleton has approximately $1-2$ million 
active remodelling sites at any given time, replacing a volume of $\sim 0.025 \mathrm{~mm}^{3}$, in each microsite. The lifespan of a single BMU is about 6 - 9 months during which several generations of osteoclasts and osteoblasts are formed. The rate of remodelling of the skeleton, as a whole, is $5-10 \%$ per year. Imbalance between resorption and formation compromises bone homeostasis, leading to bone metabolic disorders [4]. Bone remodelling is regulated by a large variety of systemic and local factors, as hormones, cytokines and growth factors, as well as by bone microdamage, changes in mechanical loading and blood calcium levels, acting through multiple extracellular and intracellular signalling networks. Systemic and local molecules may act at several steps during the differentiating pathway of the osteoclastic and osteoblastic cells. Some of them elicit different effects as cells differentiate from precursors to mature cells, while others act in particular stages of differentiation $[1,4,19]$.

\section{Bone-cell crosstalk during remodelling}

A strict control of bone remodelling, i.e. the appropriate coupling of bone resorption to formation, is required to maintain bone homeostasis. This is achieved by a complex bone-cell and humoral crosstalk.

The osteocytes are central in the bone cell crosstalk $[18,22]$. As mentioned above, they form an extensive cellular network within the mineralized bone matrix being connected among them and with the cells present in the bone surface. Thus, there is an extensive communication network among osteoblast precursors on the marrow, bone lining cells, osteoblasts, osteoclasts and osteocytes. Due to their localization and organization, osteocytes are the ideal sensors of the bone matrix status, functioning as a mechanosensing system that provides information on the quality of bone $[\underline{17}, \underline{23}]$. Events such as microdamage, ischemic situations, or any factor inducing osteocyte death or injury, interfere in the equilibrium of the osteocyte network or interrupt its intricate connections, activating the appropriate cell activities at the bone surface $[17, \underline{18}]$. Regarding this, a variety of soluble factors produced by the osteocytes and membrane pathways (mediated by connexins) induce a crosstalk with the osteoclast and osteoblast lineage cells that regulates appropriate bone resorbing and bone-forming activities at the bone surface [18].

The osteocyte is a major producer of the osteoclastogenic inducer RANKL. Additionally, it synthesizes sclerostin that is abundant in the osteocytic canalicular system [24] and is an important negative regulator of bone formation, by binding to LRP5/6 and preventing Wnt signalling [25]. Interestingly, mechanical stimulation can exert bone formation signals via osteocytes, by inhibiting the expression of sclerostin, allowing Wnt-directed bone formation to occur [19].

Also, complex interactions are established between osteoblast and osteoclast lineage cells.

Stromal cells/osteoblasts can control osteoclast differentiation and activity by cell-to-cell interactions and paracrine mechanisms. They produce M-CSF, RANKL and OPG that have a key role in this process. M-CSF is a homodimeric glycoprotein that binds to high affinity receptors expressed on cells of the monocyte/macrophage lineage. It induces the proliferation, differentiation and survival of osteoclast precursors and, also, RANK expression in osteoclast precursors. RANKL, both in membrane-bound form (mRANKL) and as a secreted protein (sRANKL), is essential for the recruitment, differentiation, activation and survival of osteoclastic cells through binding to its specific receptor RANK, which is present on the surface of osteoclast precursors and mature osteoclasts [1]. RANKL/RANK interaction activates a cascade of intracellular signalling pathways leading to the transcription of genes involved in osteoclastogenesis, as mentioned above. Instead, OPG, a circulating protein, is a decoy receptor for mRANKL and prevents RANKL/RANK interaction, inhibiting osteoclastogenesis, osteoclast activity and bone resorption $[1,4]$. Thus, OPG is a negative regulator and RANKL is a positive regulator of osteoclastogenesis, through interaction with appropriate receptors on cells of the monocyte and macrophage cell lineage. In this way, RANKL/OPG ratio is a major determinant of bone mass and better reflects environmental signals. A variety of hormones (e.g., parathyroid hormone, vitamin D3) and cytokines (e.g., pro-inflammatory cytokines) affects osteoclastic differentiation and function indirectly, acting via RANKL/OPG and M-CSF pathways $[1,4]$.

Osteoclasts play also an important role in the regulation of bone formation. Secretion of sphingosine 1-phosphate by osteoclasts seems to recruit osteoblast progenitor cells to sites of bone resorption and stimulate their differentiation [19].

Concerning intracellular pathways, the $\mathrm{Wnt} / \beta$-catenin signalling, known to be essential in the osteogenic differentiation of mesenchymal stem cells, also plays a role in the communication of osteoblasts and osteoclasts. $\beta$-catenin indirectly regulates osteoclastogenesis by raising the OPG/RANKL ratio in osteoblasts [26]. In addition, the components of the Wnt pathway are also expressed in osteoclast 
lineage cells [11]. Here, $\beta$-catenin appears to promote osteoclast precursor proliferation in response to M-CSF but blocks RANKL-induced osteoclast maturation [11]. Overall, Wnt/ $\beta$-catenin signalling appears to reduce bone resorption [11].

The ephrin/Eph system is also involved in direct communication between osteoclasts and osteoblasts. Cell surface ephrins bind tyrosine kinase receptors (ephs) and promote a bidirectional communication that links the suppression of osteoclast differentiation to the stimulation of bone formation $[19,27]$. Osteoclast precursors express ephrin-B2, which is stimulated by RANKL, and osteoblast precursors express ephB4. Reverse signalling through ephrin-B2 inhibits differentiation of osteoclast precursors, while forward signalling through ephB4 in osteoblastic precursors promotes their differentiation into osteoblasts [19,27]. Regarding this, sphingosine 1-phosphate secreted by osteoclasts stimulates ephB4 signalling, possibly leading to a shut-down of bone resorption and initiation of the formation phase in the reversal/transition phase of bone remodelling [19].

Semaphorin/plexin signalling appears also to contribute to osteoclast-osteoblast crosstalk. Osteoclast cell membranes express semaphoring 4D that inhibits osteoblast differentiation by interacting directly with its receptor, plexinB1, on osteoblast precursors. Like ephrin-B2, expression of semaphoring 4D is also increased in response to RANKL $[\underline{19}, \underline{28}]$.

\section{Immune cells involved in bone remodelling}

Immune cells also participate in bone homeostasis during normal physiology.

$\mathrm{T}$ and B-lymphocytes cooperate in the process of basal bone turnover, playing a critical role in limiting bone resorption in vivo. This protective effect is centered on a mechanism involving the synthesis of OPG by B-lineage cells (a major producer of bone marrow-derived OPG), and augmented by $\mathrm{T}$ cells, via CD40/CD40L co-stimulation [19].

Megakaryocytes reside within bone marrow and produce platelets that are needed for normal blood clotting. These cells appear to stimulate osteoblast proliferation and differentiation, express RANKL and OPG and secrete an anti-osteoclastic factor. Apparently, these effects seem to favour a net bone deposition $[19,29]$.

Osteomacs are resident tissue macrophages that, in bone, can be identified by the expression of the myeloid marker CD68, stellate morphology and location in close proximity to bone surfaces. They form a canopy over mature osteoblasts at sites of bone remodelling and appear to play a role in maintaining these cells [19].

Figure 2 shows a simplified view of the bone-cell crosstalk in the bone microenvironment, emphasizing the relevance of the M-CSF and RANKL/RANK/OPG pathways.

\section{Interplay between immune and bone cells in inflammatory environment}

The intricate interplay between bone and the immune system is well recognized in both physiological and pathological conditions. Bone and immune cells have common progenitors in bone marrow and, by sharing a number of cell surface receptors, cytokines, signalling pathways and transcription factors, affect hematopoiesis, local immune responses and bone cells function [15].

Bone is critical for the development of HSCs from which all cells of the immune system derive. Anatomically, bone marrow spaces are loosely compartmentalized, allowing bone cells and immune cells to interact and influence each other. Bone provides specialized microenvironments that are crucial to maintain the ability of self-renewal and pluripotency of HSCs (the stem-cell niches), at the same time that allow for the cell differentiation into particular immunological lineages. Early osteoblast lineage cells on the endosteal surface of bone, which is adjacent to the marrow cavity, function as critical support cells for HSCs in bone marrow $[15,30,31]$ by establishing mutual interactions, via, for instance, annexin II (an osteoblast-derived protein). HSCs can remain dormant or replicate to either self-renew or differentiate into lymphoid or myeloid precursors. The production of interleukin-10 (IL-10) by osteoblasts has been shown to promote the self-renewal of HSCs in their bone marrow located niches [31]. Osteoclasts appear also to be involved in the mobilization of HSCs [32]. In addition, the bone marrow is the site for early lymphocyte development, and end-stage and memory lymphocytes preferentially inhabit this location [15].

Cells of the immune system produce a large variety of cytokines that are important regulators of osteoclast and osteoblast function. Most act indirectly by regulating the interaction between the two cell types. Many cytokines have been shown to modulate the expression of RANK and RANKL on osteoclasts and osteoblasts, respectively, or by acting in the intracellular signalling mediated by RANK. Hence, bone homeostasis is dynamically influenced by the immune system, and lymphocyte and macrophage derived cytokines are potent mediators of 


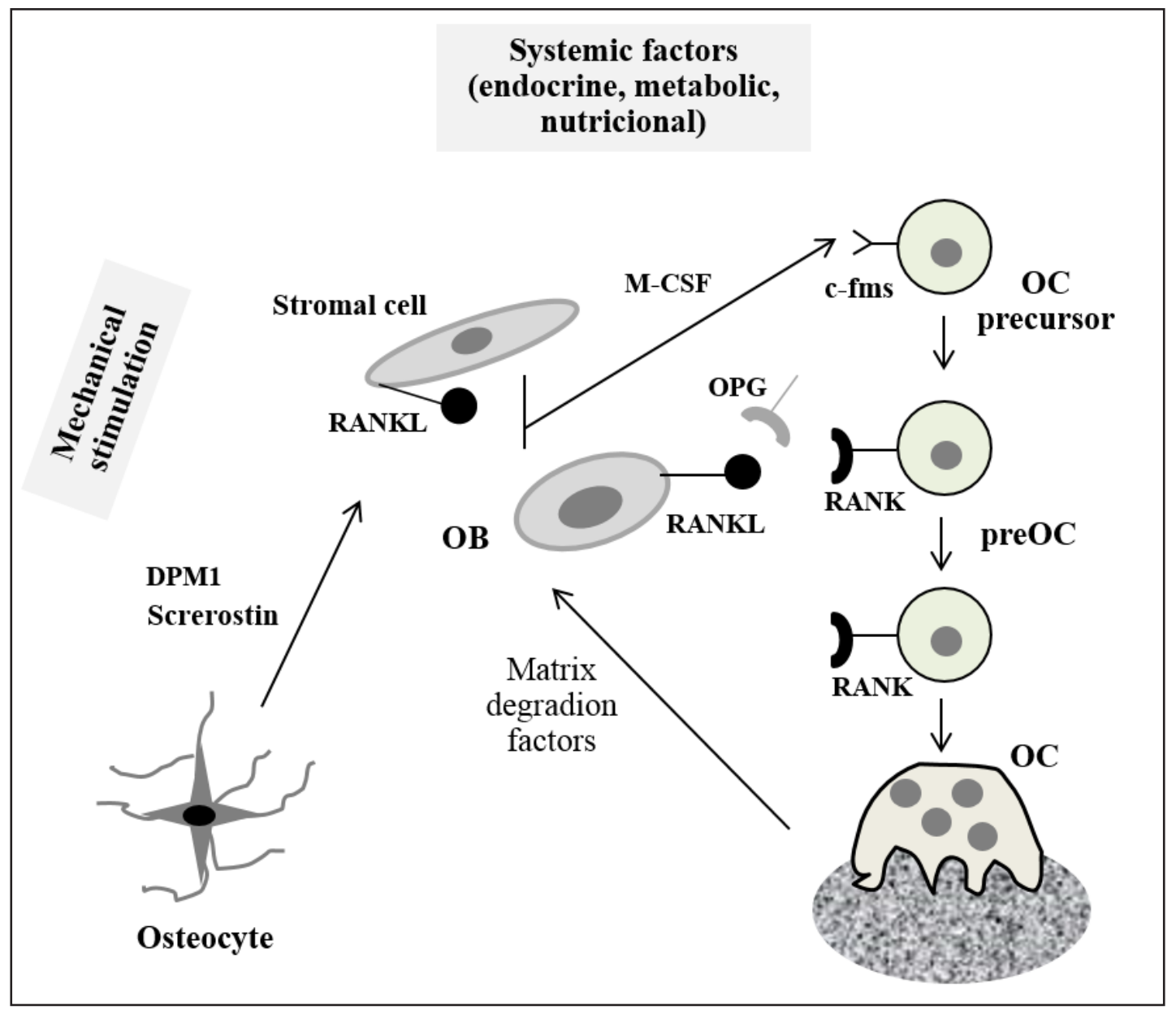

Figure 2. Simplified view of the intercellular interactions between bone cells. The relevance of the M-CSF and RANKL/RANK/OPG pathways.

$\mathrm{OB}=$ osteoblast $; \mathrm{OC}=$ osteoclast.

osteoimmunological regulation [15].

The interplay between immune system and bone is of particular relevance upon the activation of the immune system [15]. In pathological conditions associated with inflammation and activation of the immune response, activated immune cells, such as $\mathrm{T}$ lymphocytes, macrophages and dendritic cells, produce a variety of pro-inflammatory cytokines that affect bone metabolism by disturbing the balance between bone-forming osteoblasts and bone-resorbing osteoclasts, often leading to excessive osteoclast activity. Also, some pro-inflammatory cytokines appear to act in a synergic way on osteoclastogenesis and promote osteoclast function [15]. Table 1 shows the effects of several cytokines on osteoclast cells $[\underline{1}, \underline{30}, \underline{33}]$.

It is now acknowledged that activated $\mathrm{T}$ cells are powerful players as modulators of bone cell activity. They produce both RANKL and numerous cytokines that show considerable variety (e.g. IL-2, IL-4, IL5 , IL-6, IL-8, tumour necrosis factor- $\alpha$ (TNF- $\alpha$ ), TGF- $\beta$, granulocyte/macrophage colony-stimulating factor (GM-CSF), IFN- $\gamma$, etc.), so does their effect on osteoclastic and osteoblastic cells. Also, these soluble mediators affect differently the bone cells depending on the particular bone environment setting, due to the multiple possibilities of paracrine crosstalk $[\underline{15}, \underline{33}]$. In addition, the RANKL/RANK/OPG axis is the major mechanism involved in the interaction between immune and bone cells during inflammatory conditions associated with bone loss $[15,33]$.

A schematic representation for the cellular and humoral interactions between immune and bone cells is shown in Figure 3.

Following, is a brief description of some issues concerning the immune cells and cytokines that help to understand the uncoupled bone remodelling observed in inflammation-induced bone loss.

\section{T cells}

$\mathrm{T}$ cells are critical mediators of the adaptive immune response. These lymphocytes may be subdivided into major classes, with distinct functional activities, according to the expression of coreceptors, associated with the $\mathrm{T}$ cell receptor (TCR). 
Table 1. Effects of cytokines on osteoclast cells $[1,30,33]$

\begin{tabular}{|c|c|c|c|}
\hline $\begin{array}{c}\text { Cytokines } \\
\text { (Effect on bone loss) }\end{array}$ & $\begin{array}{l}\text { Main producer } \\
\text { cells }\end{array}$ & $\begin{array}{c}\text { Target cells } \\
\text { in the regulation of } \mathrm{OC}\end{array}$ & Effects on OC \\
\hline RANKL $(\uparrow)$ & $\begin{array}{l}\text { Stromal cells } / \mathrm{OB} \\
\mathrm{T} \text { cells }\end{array}$ & $\begin{array}{l}\text { OC precursor cells; } \\
\text { OC }\end{array}$ & $\begin{array}{c}\text { OC generation } \uparrow ; \\
\text { OC activation; } \\
\text { OC apoptosis } \downarrow\end{array}$ \\
\hline IL-1 ( $)$ & Macrophages & OB lineage cells & $\begin{array}{l}\text { OC generation } \uparrow ; \\
\text { OC activation }\end{array}$ \\
\hline IL-4 $(\downarrow)$ & $\begin{array}{l}\text { Th2 cells; } \\
\text { NK cells }\end{array}$ & OC precursor cells & $\begin{array}{l}\text { OC generation } \downarrow \text {; } \\
\text { RANK down-regulation }\end{array}$ \\
\hline IL-6 ( $)$ & $\begin{array}{l}\text { Th2 cells; } \\
\text { DCs }\end{array}$ & $\begin{array}{l}\text { Stromal cells/OB; } \\
\text { T cells }\end{array}$ & $\begin{array}{l}\text { OC generation } \uparrow ; \\
\text { RANKL induction }\end{array}$ \\
\hline IL-7 ( $\uparrow)$ & Stromal cells & $\begin{array}{l}\text { OC precursor cells; } \\
\text { T cells }\end{array}$ & $\begin{array}{c}\text { Indirect } \\
\text { (T cell mediated mechanisms) }\end{array}$ \\
\hline 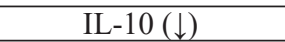 & Th2 cells & OC precursor cells & RANK signalling inhibition \\
\hline $\operatorname{IL}-12(\downarrow)$ & $\begin{array}{l}\text { Macrophages; } \\
\text { DCs }\end{array}$ & $\mathrm{T}$ cells & Indirect (via IFN- $\gamma$ induction) \\
\hline IL-17 ( $\uparrow)$ & Th17 cells & $\begin{array}{l}\text { OC precursor cells; } \\
\text { OB lineage cells }\end{array}$ & $\begin{array}{l}\text { OC generation } \uparrow \text {; } \\
\text { RANKL induction }\end{array}$ \\
\hline IL-18 ( $\downarrow)$ & $\begin{array}{l}\text { Macrophages; } \\
\text { DCs }\end{array}$ & $\mathrm{T}$ cells & Indirect (via IFN- $\gamma$ induction) \\
\hline TNF- $\alpha(\uparrow)$ & $\begin{array}{l}\text { Macrophages; } \\
\text { Th1 cells; } \\
\text { NK cells }\end{array}$ & $\begin{array}{l}\text { OC precursor cells; } \\
\text { OB lineage cells }\end{array}$ & $\begin{array}{l}\text { Mobilization of OC precursors; } \\
\text { RANKL induction; OC activation }\end{array}$ \\
\hline IFN- $\gamma(\gamma \downarrow \uparrow)$ & $\begin{array}{l}\text { Th1 cells; } \\
\text { NK cells }\end{array}$ & OC precursor cells & Variable \\
\hline $\mathrm{M}-\mathrm{CSF}(\uparrow)$ & Stromal cells/OB & OC precursor cells & OC survival and proliferation $\uparrow$ \\
\hline GM-CSF $(\downarrow)$ & $\begin{array}{c}\text { Macrophages; } \\
\text { T cells; } \\
\text { NK cells }\end{array}$ & OC precursor cells & RANKL signalling inhibition \\
\hline
\end{tabular}

$\mathrm{OC}=$ osteoclasts $; \mathrm{OB}=$ osteoblasts; $\mathrm{IL}=$ interleukin $\mathrm{Th}=\mathrm{T}$ helper; $\mathrm{RANK}=$ receptor activator of nuclear factor $\kappa \mathrm{B} ; \mathrm{RANKL}=$ receptor activator of nuclear factor $\kappa \mathrm{B}$ ligand; $\mathrm{NK}=$ natural killer; $\mathrm{DCs}=$ dendritic cells; TNF- $\alpha=$ tumour necrosis factor alpha; INF $\gamma=$ interferon gamma; M-CSF = macrophage colony-stimulating factor; GM-CSF = granulocyte macrophage colony-stimulating factor.

T cells express either $\alpha \beta$ or $\gamma \delta$ TCR on the cell surface, and these receptors are responsible for recognizing a diverse range of antigens. Most $\mathrm{T}$ cells are $\alpha \beta \mathrm{T}$ cells, a lineage which broadly expresses either CD4 or CD8 marker. CD4+ T cells, also known as helper $\mathrm{T}$ cells, represent one of the main components of the adaptive immune response. CD4 $+\mathrm{T}$ cells play arguably a central role in adaptive immunity, as they are required for almost all adaptive immune responses. They assist on B cell activation and antibody production; on macrophages induction into a higher state of activation, generally necessary for the destruction of ingested microorganisms; and on the activation of cytotoxic $\mathrm{T}$ cells to kill autologous target cells. After antigenic stimulation, naive $\mathrm{CD} 4+\mathrm{T}$ cells proliferate and may differentiate into distinct effector subsets, which have been divided, on the bases of their cytokine production profiles, into Th1 and Th2 cells [15]. Th1 cells secrete mostly IFN- $\gamma$, IL-2, IL-12, TNF- $\alpha$ and TNF- $\beta$, and are mainly involved in macrophage activation. Conversely,
Th2 cells, characterized by the secretion of IL-4, IL5 , IL-6, IL-9 and IL-13, which are potent activators of $\mathrm{B}$ cells, are indirectly involved in the elimination of extracellular microorganisms. Some of these cytokines promote osteoclastogenesis. However, Th1 and Th2 cells were both shown to inhibit osteoclast formation through the cytokines INF- $\gamma$ and IL-4, respectively [15]. There is evidence that INF- $\gamma$ functions as an anti-osteoclastogenic agent, in physiological conditions of bone turnover. However, in pathological environments, such as inflammation or bacterial infection, it is reported that the net effect of INF- $\gamma$ is inclined towards bone resorption, via antigen driven T cell activation and RANKL production [34]. Another subset of CD4+ T cells, the Th17 subset, appears to have a pro-osteoclastogenic effect. Th17 cells are relevant in bacterial infections, and are produced when naïve T cells are activated by TGF- $\beta$ and inflammatory stimuli (e.g., IL-6). These cells produce the cytokines IL-17A, IL-17F, IL-22 and IL-26, with a relevant action on neutrophils recruitment. A subset of Th17 cells also produce 


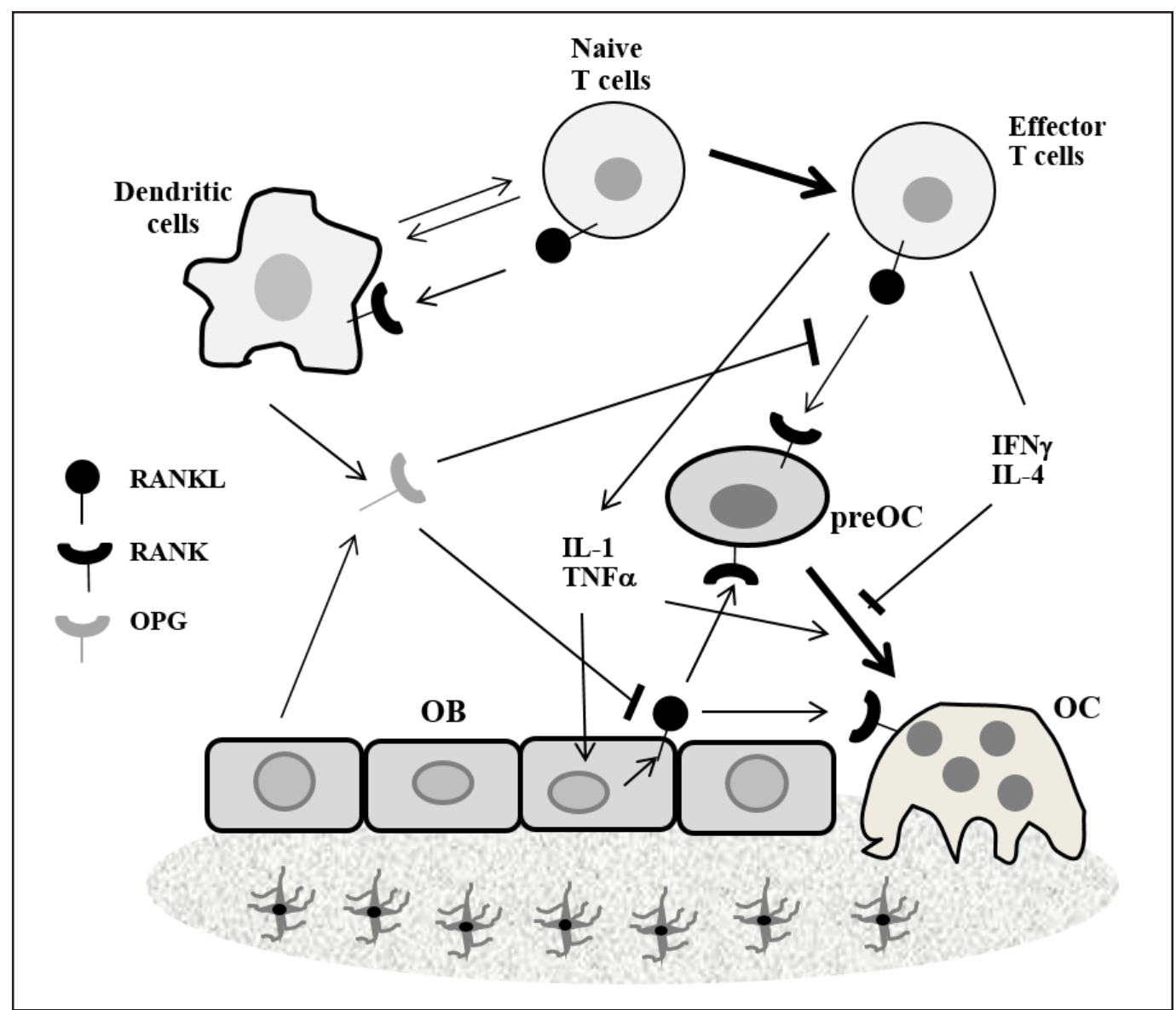

Figure 3. Simplified view of the cellular and humoral interactions within the RANK/RANKL/OPG system, between immune and bone cells. $\mathrm{OB}=$ osteoblast $\mathrm{OC}=$ osteoclast.

small amounts of INF- $\gamma$, which appear to moderate osteoclastogenic activity of Th17. The cytokine profiles of specific Th17 subsets depend on master differentiation factors present in the microenvironment during initial antigen recognition. Thus Th17 cells promote osteoclastogenesis mostly through the production of IL-17 which induces the expression of RANK on osteoclast precursors and RANKL on stromal cells and osteoblasts [31]. However, Th17 cells produce additional cytokines relevant for bone, including RANKL and TNF [31]. The effect of IL-17 is not limited to this direct influence on the osteoclastogenesis supporting cells. IL-17 further facilitates local inflammation by recruiting and activating immune cells, which leads to an abundance of inflammatory cytokines such as TNF- $\alpha$ and IL-1, in the Th17 milieu [31]. The inflammatory cytokines enhance RANKL expression on osteoclastogenesis supporting cells and activate osteoclast precursor cells by synergizing with RANKL signalling.

\section{NK T cells}

Natural killer $\mathrm{T}$ cells may also play a role in the activity of bone cells facing inflammatory conditions. They are able to rapidly release cytokines and growth factors that might influence the initiation and development of immune responses mediated by $\mathrm{T}$ and $\mathrm{B}$ cells. Additionally, they can express M-CSF and RANKL and increase osteoclast development, maturation and activity [35].

\section{B cells}

In addition to its immune function, B cells have a close and multifaceted relationship with bone cells [36]. B cells differentiate from HSCs in supportive niches found on endosteal bone surfaces. Osteoblastic lineage cells sustain HSC and B cell differentiation, at least in part, by a series of transcription factors that function in a temporal manner. This is due, in part, to the close relationship between macrophage/ osteoclast and B cell differentiation. Activated B cells play an important role in many inflammatory diseases with associated bone changes. B cell precursors and activated B cells produce RANKL [37]. Furthermore, $\mathrm{B}$ cell and $\mathrm{T}$ cell crosstalk may regulate $\mathrm{B}$ cell production of bone-active cytokines that modulate osteoclastogenesis [38] 


\section{Dendritic cells}

Dendritic cells are highly differentiated antigenpresenting cells that play a key role in the initiation and regulation of $\mathrm{T}$ cell-mediated immunity [39]. Under normal conditions, DCs are rarely localized in the bone proper or adjacent stroma, and they appear not to contribute to bone remodelling [31]. However, in the periodontal niche, particularly following periodontitis activation, both mature and immature DCs can be localized in periodontal tissues surrounding bone [40]. Upon inflammatory stimuli, DCs can form aggregates with $\mathrm{T}$ cells in inflammatory foci, and interact through CD40/CD40L, or RANK/ RANKL signalling, being described as indirect players influencing inflammation-induced bone loss through the regulation of $\mathrm{T}$ cell activity [40]. Additionally, RANKL signalling appears also to modulate DC function, namely by prolonging DC survival [15].

Dendritic cells differentiate from the hematopoietic monocyte/macrophage progenitor cell lineage and, due to the common origin, it was reported that, in vitro, DCs can transdifferentiate into osteoclasts during their early stage of development in the presence of GM-CSF and pro-inflammatory cytokines, suggesting that DC might directly contribute to osteoclastogenesis [31].

\section{Neutrophils}

Neutrophils form an essential part of the innate immune system. They are normally present in blood stream. During the acute phase of inflammation, namely as a result of bacterial infection, neutrophils are one of first cells to migrate towards the site of inflammation [31]. Inflammatory-associated bony lesions, as in periodontitis, show neutrophils infiltration [41]. Activated neutrophils synthesize large amounts of proteins and lipids that participate in the inflammatory process. Neutrophils from inflammatory sites express high levels of RANKL [31]. Also, they strongly upregulate the expression of mRANKL after lipopolysaccharides (LPS) stimulation and thus have the capacity to activate osteoclast resorption through neutrophil-osteoclast interactions [42].

\section{BONE CELLS ACTIVITY DURING PERI- IMPLANTITIS}

Long-term stability of dental implants demands its osseointegration in the alveolar bone. The osteoblast lineage cells, following their recruitment and differentiation, synthesize the bone collagenous organic matrix and control its mineralization. The homeostasis and mechanical performance of the peri-implant bone depend on a proper remodelling process involving the concerted coupled activities of the bone-forming osteoblasts and the bone resorbing osteoclasts. Additionally, osteocytes are key players in maintaining implant stability, due to their role in assuring the proper physiological turnover of the osseointegrated implant by modulating the bone cells activity in response to mechanical stress, i.e. by occlusal load of the implant, and in response to systemic and local factors interacting in the local microenvironment $[7,43]$.

Peri-implantitis is an inflammatory condition that affects bone and soft tissues around implants that may result in the loss of supporting alveolar bone. Persistent bacterial contamination and functional overloading, which may lead to chronic inflammation, have been suggested as the main etiological factors for peri-implantitis [44].

The immune system responds to the bacterial challenge by mobilizing neutrophils, macrophages, $\mathrm{T}$ cells and B cells, which then migrate into the lesion inducing a local inflammatory response in the soft and bone tissue [45]. Recruited and activated immune cells are a source of a large variety of cytokines that modulate local cellular and humoral responses, by complex signalling and trafficking mechanisms, playing a strategic role in the initiation and progression of the inflammatory process [46]. Proinflammatory cytokines (e.g. TNF- $\alpha$, INF- $\gamma$, IL- $1 \beta$, IL-6, IL-12, IL-17 and RANKL), anti-inflammatory cytokines (e.g. IL-4, IL-10) and chemokines (e.g. IL8 , monocyte chemoattractant protein-1, macrophage inflammatory protein-1 $\alpha$ ) have been suggested to be important mediators of inflammation and immunity in the pathogenesis of peri-implantitis [47-49]. Imbalances between pro-inflammatory and antiinflammatory cytokines usually hinder the resolution of inflammation, leading to the maintenance of disease and tissue destruction [46]. Further, the bone and immune-inflammatory cells interact with each other and release common cytokines involved in bone damage [33]. For instance, the osteoclastogenic chemokine IL-8 may also be produced by osteoclasts in certain conditions [33]. Thus, alveolar bone loss occurs as a result of direct and indirect immune/bone cells mediated mechanisms [50].

A high number of studies points for an immuneinflammatory induced osteoclastogenesis as the central pathological hallmark of peri-implantitis, resulting in uncoupled bone resorption to bone formation, ending in alveolar bone loss. 
Analysis of the peri-implant crevicular fluid (PICF) composition from diseased and healthy implants concerning pro- and anti-inflammatory cytokines, matrix metalloproteinases, matrix proteins and bone turnover markers have been providing relevant information on the activity of local bone cells in an attempt to understand the mechanisms leading to the induced alveolar bone loss in peri-implantitis $[43,51]$. Although a number of methodological limitations arises, a variety of studies shows increased levels of the pro-inflammatory cytokines IL-1 $\beta$, IL-6, IL-17, TNF- $\alpha$, IL-12, but especially IL-1 $\beta$, in the PICF of implants with peri-implantitis, when compared with healthy implants [52-62]. Levels of the chemokine IL-8, essential for leukocyte attraction and trafficking into tissues under inflammatory conditions, were also reported [52,57], but differences were not found between healthy and diseased implants. Concentrations of the classical anti-inflammatory cytokines IL-4 and IL-10 were analyzed in few studies. In implants with peri-implantitis, similar [ $[\underline{57}$, 58] or lower [55] levels of IL-4 and/or IL-10 were reported, despite that higher levels of IL-10 were also described [52]

The underlying mechanism of the immuneinflammatory process leading to bone resorption appears to be centered on RANKL. As mentioned above, cells involved in the local host reaction produce several cytokines that induce the synthesis of this osteoclastogenic factor by stromal cells and osteoblasts. Additionally, activated immune cells are also RANKL producers; expression of this molecule is induced by a critical concentration of proinflammatory mediators and LPS. Thus direct, indirect and synergic RANKL induced osteoclastogenesis play a role. Regarding the PICF levels, results are not consistent, and increased $[63,64]$, lower [65] and similar $[58,66]$ RANKL levels have been reported when comparing untreated diseased implants with healthy implants. However, the interpretation of these results cannot be dissociated from the overall RANKL/RANK/OPG system and the RANKL/OPG ratio, as the biological activity of RANKL is regulated by its decoy receptor OPG. Nonetheless, reported RANKL/OPG ratio also differs, showing to be similar [63-65] and increased [ 58], between untreated peri-implantitis-affected and healthy implants' PICF.

Sclerostin, expressed by the osteocytes in the bone matrix, and a negative regulator of bone formation, is pointed also to be important in bone loss observed in peri-implantitis [63]. This molecule is reported to be up-regulated by pro-inflammatory cytokines [67], as well as excessive load [요].
Further, in addition to the induced osteoclast resorption, some data strongly suggest that a disturbed behaviour of the local osteoblast cells may also contribute to the failure of implant osteointegration. It has been reported [43] that expression gene and protein levels of typical bone matrix molecules, namely osteopontin, osteocalcin, COL9A1 were downregulated in peri-implantitis bone tissue, as compared to healthy samples. Also, expression of the osteogenic transcription factor Runx-2 and BMP-7 were decreased in peri-implantitis samples. In addition, reduced FGF-18 was also noted; this factor is known to play a role in bone development and disease [69]. Meanwhile, expression of matrix metalloproteinases, such as MMP-7 and MMP- 8 were upregulated [43], in line with previous results [70]. It was also shown that the osteoblastic lineage cells derived from peri-implantitis bone samples exhibited a fibro-osteoblastic phenotype, with enhanced expression of fibrocytic markers and lower expression of Runx-2 [43]. This study suggests that the formation of a tissue that is more fibrous and expresses less osteogenic markers may be a contributing factor to the loss of osteointegration [43].

Fibroblasts may also play a role in the pathogenesis of peri-implantitis, namely by stimulating matrix degradation according to that reported previously [71]. In line with this, a more recent study showed an upregulation of inflammatory mediators and MMPs, in peri-implantitis fibroblasts [72]. Further, in periodontitis, fibroblasts appear also to participate in the regulation of bone cells' activity. They produce OPG in response to bacterial LPS and IL1 , suggesting a protective role to limit osteoclast formation. However, upon stimulation by LPS, gingival fibroblasts may too enhance chronic inflammatory processes through IL-1, IL-6 and IL-8 production, thus being indirectly involved in RANKLmediated osteoclastogenesis [73] .

Data on the levels of immune-inflammatory and bone turnover markers greatly contribute to the clarification of the complex cellular and molecular crosstalk underlying bone loss in peri-implantitis. However, as stressed on a recent systematic review [51] that compared the PICF levels of these markers in healthy and diseased implants, the available information is mostly concerned with few classical pro-inflammatory markers and, more recently, with factors relevant on the osteoblast/osteoclast interaction. The comparison of several important cytokines involved in innate, T-helper and T-regulatory responses, such as IFN- $\gamma$, IL-23, IL-2, IL-11, TGF- $\beta$, macrophage inflammatory proteins, G-CSF, GM-CSF has never been properly performed [51]. Also, not much data is available 
regarding the bone cell crosstalk and also the interplay between immune and bone cells in the context of the peri-implantitis. Thus, basic level information on this issue is still quite limited, especially when considering the wide number of cytokines involved and the complexity of the cellular and humoral crosstalk of this osteoimmunological condition.

A simplified view of the immune-inflammatory reaction leading to bone loss in peri-implantitis is depicted in Figure 4.

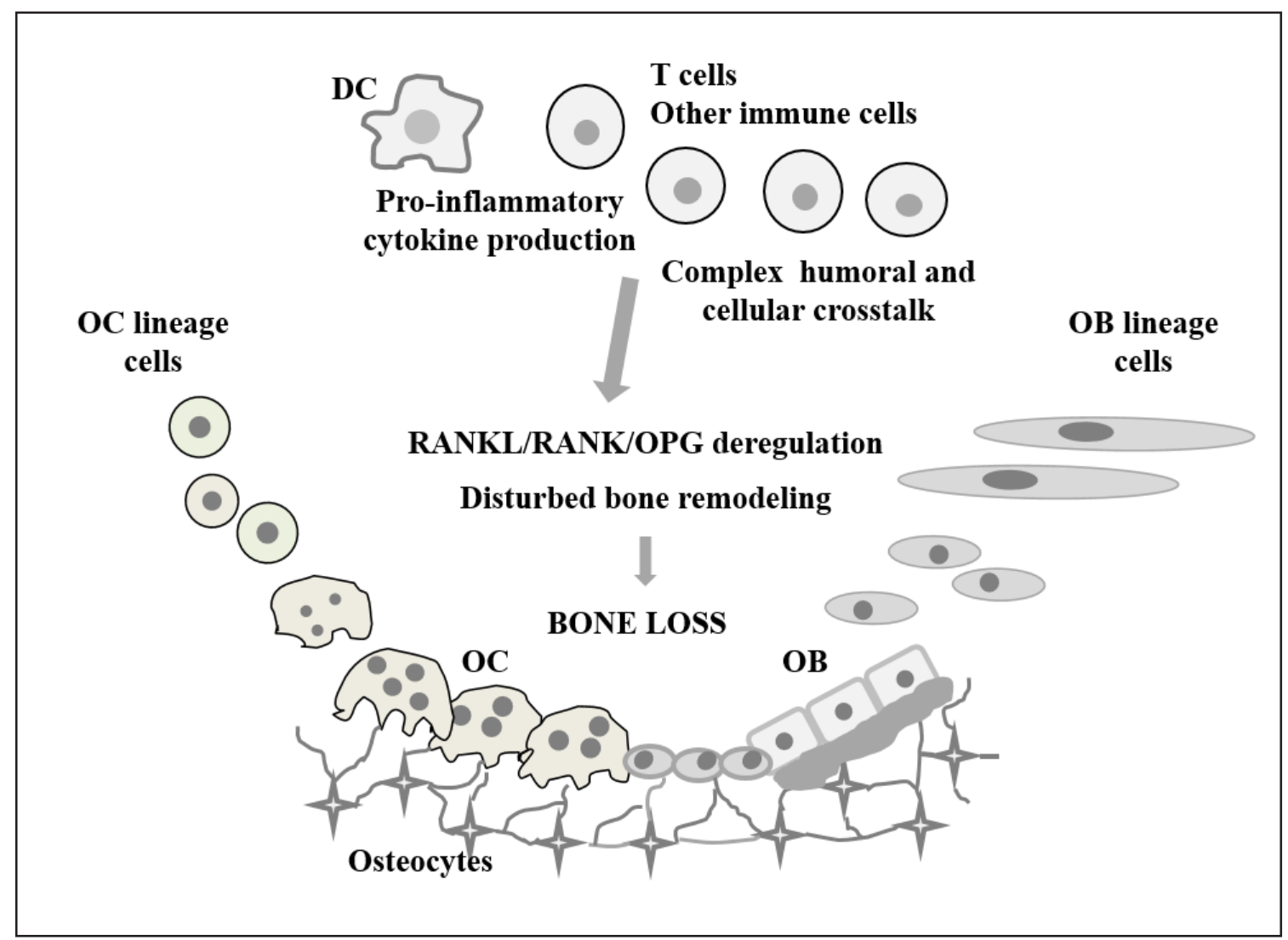

Figure 4. Model of the immune-inflammatory activation in peri-implantitis, leading to the alveolar bone loss. $\mathrm{DC}=$ dendritic cell; $\mathrm{OB}=$ osteoblast $; \mathrm{OC}=$ osteoclast

\section{CONCLUSIONS}

Alveolar bone loss is a hallmark of peri-implantitis. Most data points to an immune-inflammatory induced osteoclast differentiation and function, as the major underlying mechanism to the uncoupled bone resorption to bone formation. Further, receptor activator of nuclear factor $\kappa \mathrm{B}$ ligand/ receptor activator of nuclear factor $\kappa \mathrm{B}$ interaction is considered a key pathway in this process. Elevated levels of receptor activator of nuclear factor $\kappa \mathrm{B}$ ligand, arising from cytokine-induced synthesis by stromal/osteoblast cells and also produced by a variety of immune-inflammatory cells, substantiate the increased osteoclastogenesis. In addition to the osteoclast-lineage cells, the disturbed functioning of osteoblasts, reflected by the possible expression of a fibro-osteoblastic phenotype, was also suggested. Thus, the eventual formation of an unsuited bone mineralized matrix would also contribute to the impairment of bone remodelling.

Analysis of the PICF composition on immuneinflammatory and bone turnover markers has been providing relevant information on the activity of bone cells in the peri-implantitis environment. However, available information is still limited, as it mostly addresses few classical markers and is hindered by the variability of the used protocols. Due to the complexity of the events associated to peri-implantitis much more data are needed. In this regard, a remarkable growing interest in a "bottom-up" approach is noticed, i.e. a basic level research focusing on the cellular and humoral crosstalk in the context of an integrated view of the osteoimmunologic interplay occurring in the periimplantitis environment. This certainly will contribute to a more complete picture on the uncoupled bone cells dynamics leading to bone loss associated peri-implantitis, opening new ways for innovative therapeutic options. 


\section{ACKNOWLEDGMENTS AND DISCLOSURE STATEMENTS}

The authors report no conflicts of interest related to this study.

\section{REFERENCES}

1. Datta HK, Ng WF, Walker JA, Tuck SP, Varanasi SS. The cell biology of bone metabolism. J Clin Pathol. 2008 May;61(5):577-87. [Medline: 18441154] [doi: 10.1136/jcp.2007.048868]

2. Karsenty G, Ferron M. The contribution of bone to whole-organism physiology. Nature. 2012 Jan 18;481(7381):314-20. [Medline: 22258610] [doi: 10.1038/nature10763]

3. Fukumoto S, Martin TJ. Bone as an endocrine organ. Trends Endocrinol Metab. 2009 Jul;20(5):230-6. [Medline: 19546009] [doi: 10.1016/j.tem.2009.02.001]

4. Teti A. Bone development: overview of bone cells and signaling. Curr Osteoporos Rep. 2011 Dec;9(4):264-73. [Medline: 21948208] [doi: 10.1007/s11914-011-0078-8]

5. Seeman E. Bone modeling and remodeling. Crit Rev Eukaryot Gene Expr. 2009;19(3):219-33. [Medline: 19883366] [doi: 10.1615/CritRevEukarGeneExpr.v19.i3.40]

6. Robling AG, Turner $\mathrm{CH}$. Mechanical signaling for bone modeling and remodeling. Crit Rev Eukaryot Gene Expr. 2009;19(4):319-38. [Medline: 19817708] [PMC free article: 3743123] [doi: 10.1615/CritRevEukarGeneExpr.v19.i4.50]

7. Long F. Building strong bones: molecular regulation of the osteoblast lineage. Nat Rev Mol Cell Biol. 2011 Dec 22;13(1):27-38. [Medline: 22189423] [doi: 10.1038/nrm3254]

8. Hayrapetyan A, Jansen JA, van den Beucken JJ. Signaling pathways involved in osteogenesis and their application for bone regenerative medicine. Tissue Eng Part B Rev. 2015 Feb;21(1):75-87. [Medline: 25015093] [doi: 10.1089/ten.TEB.2014.0119]

9. Chen G, Deng C, Li YP. TGF- $\beta$ and BMP signaling in osteoblast differentiation and bone formation. Int J Biol Sci. 2012;8(2):272-88. [Medline: 22298955] [PMC free article: 3269610$]$ [doi: 10.7150/ijbs.2929]

10. Baek WY, Kim JE. Transcriptional regulation of bone formation. Front Biosci (Schol Ed). 2011 Jan 1;3:126-35. [Medline: 21196363]

11. Monroe DG, McGee-Lawrence ME, Oursler MJ, Westendorf JJ. Update on Wnt signaling in bone cell biology and bone disease. Gene. 2012 Jan 15;492(1):1-18. [Medline: 22079544] [PMC free article: 3392173] [doi: $10.1016 /$ j.gene.2011.10.044]

12. Glass DA 2nd, Bialek P, Ahn JD, Starbuck M, Patel MS, Clevers H, Taketo MM, Long F, McMahon AP, Lang RA, Karsenty G. Canonical Wnt signaling in differentiated osteoblasts controls osteoclast differentiation. Dev Cell. 2005 May;8(5):751-64. [Medline: 15866165] [doi: 10.1016/j.devcel.2005.02.017]

13. Liu TM, Lee EH. Transcriptional regulatory cascades in Runx2-dependent bone development. Tissue Eng Part B Rev. 2013 Jun;19(3):254-63. [Medline: 23150948] [PMC free article: 3627420] [doi: 10.1089/ten.teb.2012.0527]

14. Boyce BF, Rosenberg E, de Papp AE, Duong LT. The osteoclast, bone remodelling and treatment of metabolic bone disease. Eur J Clin Invest. 2012 Dec;42(12):1332-41. [Medline: 22998735] [doi: 10.1111/j.1365-2362.2012.02717.x]

15. Walsh MC, Kim N, Kadono Y, Rho J, Lee SY, Lorenzo J, Choi Y. Osteoimmunology: interplay between the immune system and bone metabolism. Annu Rev Immunol. 2006;24:33-63. [Medline: 16551243] [doi: 10.1146/annurev.immunol.24.021605.090646]

16. Peruzzi B, Teti A. The physiology and pathophysiology of the osteoclasts. Clinic Rev Bone Miner Metab 2012 Apl;10: 71-97. [doi: 10.1007/s12018-011-9086-6]

17. Santos A, Bakker AD, Klein-Nulend J. The role of osteocytes in bone mechanotransduction. Osteoporos Int. 2009 Jun;20(6):1027-31. [Medline: 19340507] [doi: 10.1007/s00198-009-0858-5]

18. Bonewald LF. The amazing osteocyte. J Bone Miner Res. 2011 Feb;26(2):229-38. [Medline: 21254230] [PMC free article: 3179345$]$ [doi: $10.1002 / \mathrm{jbmr} .320$ ]

19. Raggatt LJ, Partridge NC. Cellular and molecular mechanisms of bone remodeling. J Biol Chem. 2010 Aug 13; 285(33):25103-8. [Medline: 20501658] [PMC free article: 2919071] [doi: 10.1074/jbc.R109.041087]

20. Ryu J, Kim HJ, Chang EJ, Huang H, Banno Y, Kim HH. Sphingosine 1-phosphate as a regulator of osteoclast differentiation and osteoclast-osteoblast coupling. EMBO J. 2006 Dec 13;25(24):5840-51. [Medline: 17124500] [PMC free article: 1698879] [doi: 10.1038/sj.emboj.7601430]

21. Henriksen K, Neutzsky-Wulff AV, Bonewald LF, Karsdal MA. Local communication on and within bone controls bone remodeling. Bone. 2009 Jun;44(6):1026-33. [Medline: 19345750] [doi: 10.1016/j.bone.2009.03.671]

22. Neve A, Corrado A, Cantatore FP. Osteocytes: central conductors of bone biology in normal and pathological conditions. Acta Physiol (Oxf). 2012 Mar;204(3):317-30. [Medline: 22099166] [doi: 10.1111/j.1748-1716.2011.02385.x] 
23. Harris SE, Gluhak-Heinrich J, Harris MA, Yang W, Bonewald LF, Riha D, Rowe PS, Robling AG, Turner CH, Feng JQ, McKee MD, Nicollela D. DMP1 and MEPE expression are elevated in osteocytes after mechanical loading in vivo: theoretical role in controlling mineral quality in the perilacunar matrix. J Musculoskelet Neuronal Interact. 2007 OctDec;7(4):313-5. [Medline: 18094489] [PMC free article: 3357082]

24. Winkler DG, Sutherland MK, Geoghegan JC, Yu C, Hayes T, Skonier JE, Shpektor D, Jonas M, Kovacevich BR, Staehling-Hampton K, Appleby M, Brunkow ME, Latham JA. Osteocyte control of bone formation via sclerostin, a novel BMP antagonist. EMBO J. 2003 Dec 1;22(23):6267-76. [Medline: 14633986] [PMC free article: 291840] [doi: $10.1093 / \mathrm{emboj} / \mathrm{cdg} 599$ ]

25. Li X, Zhang Y, Kang H, Liu W, Liu P, Zhang J, Harris SE, Wu D. Sclerostin binds to LRP5/6 and antagonizes canonical Wnt signaling. J Biol Chem. 2005 May 20;280(20):19883-7. [Medline: 15778503] [doi: 10.1074/jbc.M413274200]

26. Glass DA 2nd, Bialek P, Ahn JD, Starbuck M, Patel MS, Clevers H, Taketo MM, Long F, McMahon AP, Lang RA, Karsenty G. Canonical Wnt signaling in differentiated osteoblasts controls osteoclast differentiation. Dev Cell. 2005 May;8(5):751-64. [Medline: 15866165] [doi: 10.1016/j.devcel.2005.02.017]

27. Pasquale EB. Eph-ephrin bidirectional signaling in physiology and disease. Cell. 2008 Apr 4;133(1):38-52. [Medline: 18394988] [doi: 10.1016/j.cell.2008.03.011]

28. Negishi-Koga T, Shinohara M, Komatsu N, Bito H, Kodama T, Friedel RH, Takayanagi H. Suppression of bone formation by osteoclastic expression of semaphorin 4D. Nat Med. 2011 Oct 23;17(11):1473-80. [Medline: 22019888] [doi: $10.1038 / \mathrm{nm} .2489]$

29. Ciovacco WA, Cheng YH, Horowitz MC, Kacena MA. Immature and mature megakaryocytes enhance osteoblast proliferation and inhibit osteoclast formation. J Cell Biochem. 2010 Mar 1;109(4):774-81. [Medline: 20052670] [PMC free article: 3095430] [doi: 10.1002/jcb.22456]

30. Takayanagi H. Osteoimmunology: shared mechanisms and crosstalk between the immune and bone systems. Nat Rev Immunol. 2007 Apr;7(4):292-304. [Medline: 17380158] [doi: 10.1038/nri2062]

31. Mori G, D'Amelio P, Faccio R, Brunetti G. The Interplay between the bone and the immune system. Clin Dev Immunol. 2013;2013:720504. [Medline: 23935650] [PMC free article: 3725924] [doi: 10.1155/2013/720504]

32. Kollet O, Dar A, Shivtiel S, Kalinkovich A, Lapid K, Sztainberg Y, Tesio M, Samstein RM, Goichberg P, Spiegel A, Elson A, Lapidot T. Osteoclasts degrade endosteal components and promote mobilization of hematopoietic progenitor cells. Nat Med. 2006 Jun;12(6):657-64. [Medline: 16715089] [doi: 10.1038/nm1417]

33. Zupan J, Jeras M, Marc J. Osteoimmunology and the influence of pro-inflammatory cytokines on osteoclasts. Biochem Med (Zagreb). 2013;23(1):43-63. [Medline: 23457765] [PMC free article: 3900089] [doi: 10.11613/BM.2013.007]

34. Gao Y, Grassi F, Ryan MR, Terauchi M, Page K, Yang X, Weitzmann MN, Pacifici R. IFN-gamma stimulates osteoclast formation and bone loss in vivo via antigen-driven T cell activation. J Clin Invest. 2007 Jan;117(1):122-32. Epub 2006 Dec 14. [Medline: 17173138] [PMC free article: 1697800] [doi: 10.1172/JCI30074]

35. Hu M, Bassett JH, Danks L, Howell PG, Xu K, Spanoudakis E, Kotsianidis I, Boyde A, Williams GR, Horwood N, Roberts IA, Karadimitris A. Activated invariant NKT cells regulate osteoclast development and function. J Immunol. 2011 Mar 1;186(5):2910-7. [Medline: 21278350] [doi: 10.4049/jimmunol.1002353]

36. Horowitz MC, Fretz JA, Lorenzo JA. How B cells influence bone biology in health and disease. Bone. 2010 Sep;47(3): 472-9. [Medline: 20601290] [PMC free article: 2941392] [doi: 10.1016/j.bone.2010.06.011]

37. Manabe N, Kawaguchi H, Chikuda H, Miyaura C, Inada M, Nagai R, Nabeshima Y, Nakamura K, Sinclair AM, Scheuermann RH, Kuro-o M. Connection between B lymphocyte and osteoclast differentiation pathways. J Immunol. 2001 Sep 1;167(5):2625-31. [Medline: 11509604] [doi: 10.4049/jimmunol.167.5.2625]

38. Choi Y, Kim JJ. B cells activated in the presence of Th1 cytokines inhibit osteoclastogenesis. Exp Mol Med. 2003 Oct 31;35(5):385-92. [Medline: 14646592] [doi: 10.1038/emm.2003.51]

39. Steinman RM, Banchereau J. Taking dendritic cells into medicine. Nature. 2007 Sep 27;449(7161):419-26. [Medline: 17898760 ] [doi: $10.1038 /$ nature06175]

40. Cirrincione C, Pimpinelli N, Orlando L, Romagnoli P. Lamina propria dendritic cells express activation markers and contact lymphocytes in chronic periodontitis. J Periodontol. 2002 Jan;73(1):45-52. [Medline: 11846200] [doi: 10.1902/jop.2002.73.1.45]

41. Kantarci A, Oyaizu K, Van Dyke TE. Neutrophil-mediated tissue injury in periodontal disease pathogenesis: findings from localized aggressive periodontitis. J Periodontol. 2003 Jan;74(1):66-75. [Medline: 12593599] [doi: 10.1902/jop.2003.74.1.66]

42. Chakravarti A, Raquil MA, Tessier P, Poubelle PE. Surface RANKL of Toll-like receptor 4-stimulated human neutrophils activates osteoclastic bone resorption. Blood. 2009 Aug 20;114(8):1633-44. [Medline: 19546479] [doi: 10.1182/blood-2008-09-178301]

43. Schminke B, Vom Orde F, Gruber R, Schliephake H, Bürgers R, Miosge N. The pathology of bone tissue during peri-implantitis. J Dent Res. 2015 Feb;94(2):354-61. [Medline: 25406169] [PMC free article: 4438728] [doi: $10.1177 / 0022034514559128]$

44. De Smet E, van Steenberghe D, Quirynen M, Naert I. The influence of plaque and/or excessive loading on marginal soft and hard tissue reactions around Brånemark implants: a review of literature and experience. Int J Periodontics Restorative Dent. 2001 Aug;21(4):381-93. Review. [Medline: 11519707] 
45. Belibasakis GN. Microbiological and immuno-pathological aspects of peri-implant diseases. Arch Oral Biol. 2014 Jan;59(1):66-72. [Medline: 24209597] [doi: 10.1016/j.archoralbio.2013.09.013]

46. Bryant VL, Slade CA. Chemokines, their receptors and human disease: the good, the bad and the itchy. Immunol Cell Biol. 2015 Apr;93(4):364-71. [Medline: 25895814] [doi: 10.1038/icb.2015.23]

47. Li JY, Wang HL. Biomarkers associated with periimplant diseases. Implant Dent. 2014 Oct;23(5):607-11. [Medline: 25192154] [doi: 10.1097/ID.0000000000000129]

48. Candel-Martí ME, Flichy-Fernández AJ, Alegre-Domingo T, Ata-Ali J, Peñarrocha-Diago MA. Interleukins IL-6, IL-8, IL-10, IL-12 and periimplant disease. An update. Med Oral Patol Oral Cir Bucal. 2011 Jul 1;16(4):e518-21. Review. [Medline: 21196889]

49. Javed F, Al-Hezaimi K, Salameh Z, Almas K, Romanos GE. Proinflammatory cytokines in the crevicular fluid of patients with peri-implantitis. Cytokine. 2011 Jan;53(1):8-12. [Medline: 20870421] [doi: 10.1016/j.cyto.2010.08.013]

50. Lang NP, Berglundh T; Working Group 4 of Seventh European Workshop on Periodontology. Periimplant diseases: where are we now?--Consensus of the Seventh European Workshop on Periodontology. J Clin Periodontol. 2011 Mar;38 Suppl 11:178-81. [Medline: 21323713] [doi: 10.1111/j.1600-051X.2010.01674.x]

51. Duarte PM, Serrão CR, Miranda TS, Zanatta LC, Bastos MF, Faveri M, Figueiredo LC, Feres M. Could cytokine levels in the peri-implant crevicular fluid be used to distinguish between healthy implants and implants with peri-implantitis? A systematic review. J Periodontal Res. 2016 Jan 16. [Medline: 26774043] [doi: 10.1111/jre.12354]

52. Ata-Ali J, Flichy-Fernández AJ, Alegre-Domingo T, Ata-Ali F, Palacio J, Peñarrocha-Diago M. Clinical, microbiological, and immunological aspects of healthy versus peri-implantitis tissue in full arch reconstruction patients: a prospective cross-sectional study. BMC Oral Health. 2015 Apr 1;15:43. [Medline: 25888355] [PMC free article: 4391105] [doi: 10.1186/s12903-015-0031-9]

53. Wang HL, Garaicoa-Pazmino C, Collins A, Ong HS, Chudri R, Giannobile WV. Protein biomarkers and microbial profiles in peri-implantitis. Clin Oral Implants Res. 2016 Sep;27(9):1129-36. [Medline: 26424287] [doi: 10.1111/clr.12708]

54. Yaghobee S, Khorsand A, Rasouli Ghohroudi AA, Sanjari K, Kadkhodazadeh M. Assessment of interleukin1beta and interleukin-6 in the crevicular fluid around healthy implants, implants with peri-implantitis, and healthy teeth: a cross-sectional study. J Korean Assoc Oral Maxillofac Surg. 2014 Oct;40(5):220-4. [Medline: 25368834] [PMC free article: $\underline{4217267]}$ [doi: 10.5125/jkaoms.2014.40.5.220]

55. Casado PL, Canullo L, de Almeida Filardy A, Granjeiro JM, Barboza EP, Leite Duarte ME. Interleukins $1 \beta$ and 10 expressions in the periimplant crevicular fluid from patients with untreated periimplant disease. Implant Dent. 2013 Apr;22(2):143-50. [Medline: 23459153] [doi: 10.1097/ID.0b013e3182818792]

56. Darabi E, Kadkhoda Z, Amirzargar A. Comparison of the levels of tumor necrosis factor- $\alpha$ and interleukin-17 in gingival crevicular fluid of patients with peri-implantitis and a control group with healthy implants. Iran J Allergy Asthma Immunol. 2013 Mar;12(1):75-80. [Medline: 23454782]

57. everino VO, Napimoga MH, de Lima Pereira SA. Expression of IL-6, IL-10, IL-17 and IL-8 in the peri-implant crevicular fluid of patients with peri-implantitis. Arch Oral Biol. 2011 Aug;56(8):823-8. [Medline: 21306703] [doi: 10.1016/j.archoralbio.2011.01.006]

58. Duarte PM, de Mendonça AC, Máximo MB, Santos VR, Bastos MF, Nociti FH. Effect of anti-infective mechanical therapy on clinical parameters and cytokine levels in human peri-implant diseases. J Periodontol. 2009 Feb;80(2):234-43. [Medline: 19186963] [doi: 10.1902/jop.2009.070672]

59. Zhang Y, Wang C, Jinbu Y, Itoh H, Kusama M. Increased IL-6 levels in periimplant crevicular fluid correlate with periimplantitis. Oral Med Pathol 2005 Jan; 10(3):95-9. [doi: 10.3353/omp.10.95]

60. Murata M, Tatsumi J, Kato Y, Suda S, Nunokawa Y, Kobayashi Y, Takeda H, Araki H, Shin K, Okuda K, Miyata T, Yoshie H. Osteocalcin, deoxypyridinoline and interleukin-1beta in peri-implant crevicular fluid of patients with peri-implantitis. Clin Oral Implants Res. 2002 Dec;13(6):637-43. [Medline: 12519339] [doi: 10.1034/j.1600-0501.2002.130610.x]

61. Aboyoussef H, Carter C, Jandinski JJ, Panagakos FS. Detection of prostaglandin E2 and matrix metalloproteinases in implant crevicular fluid. Int J Oral Maxillofac Implants. 1998 Sep-Oct;13(5):689-96. [Medline: 9796154]

62. Kao RT, Curtis DA, Richards DW, Preble J. Increased interleukin-1 beta in the crevicular fluid of diseased implants. Int J Oral Maxillofac Implants. 1995 Nov-Dec;10(6):696-701. [Medline: $\underline{8530172]}$

63. Rakic M, Struillou X, Petkovic-Curcin A, Matic S, Canullo L, Sanz M, Vojvodic D. Estimation of bone loss biomarkers as a diagnostic tool for peri-implantitis. J Periodontol. 2014 Nov;85(11):1566-74. [Medline: 24878328] [doi: 10.1902/jop.2014.140069]

64. Rakic M, Lekovic V, Nikolic-Jakoba N, Vojvodic D, Petkovic-Curcin A, Sanz M. Bone loss biomarkers associated with peri-implantitis. A cross-sectional study. Clin Oral Implants Res. 2013 Oct;24(10):1110-6. [Medline: 22708989] [doi: $10.1111 / \mathrm{j} .1600-0501.2012 .02518 . \mathrm{x}]$

65. Arikan F, Buduneli N, Lappin DF. C-telopeptide pyridinoline crosslinks of type I collagen, soluble RANKL, and osteoprotegerin levels in crevicular fluid of dental implants with peri-implantitis: a case-control study. Int J Oral Maxillofac Implants. 2011 Mar-Apr;26(2):282-9. [Medline: 21483881]

66. Sarlati F, Sattari M, Gazar AG, Rafsenjani AN. Receptor activator of nuclear factor kappa B ligand (RANKL) levels in peri-implant crevicular fluid. Iran J Immunol. 2010 Dec;7(4):226-33. [Medline: 21189445] 
67. Vincent C, Findlay DM, Welldon KJ, Wijenayaka AR, Zheng TS, Haynes DR, Fazzalari NL, Evdokiou A, Atkins GJ. Pro-inflammatory cytokines TNF-related weak inducer of apoptosis (TWEAK) and TNFalpha induce the mitogenactivated protein kinase (MAPK)-dependent expression of sclerostin in human osteoblasts. J Bone Miner Res. 2009 Aug;24(8):1434-49. [Medline: 19292615] [doi: 10.1359/jbmr.090305]

68. Suva LJ. Sclerostin and the unloading of bone. J Bone Miner Res. 2009 Oct;24(10):1649-50. [Medline: 19757998] [doi: 10.1359/jbmr.090815]

69. Su N, Du X, Chen L. FGF signaling: its role in bone development and human skeleton diseases. Front Biosci. 2008 Jan 1;13:2842-65. [Medline: 17981758] [doi: 10.2741/2890]

70. Kivelä-Rajamäki M, Maisi P, Srinivas R, Tervahartiala T, Teronen O, Husa V, Salo T, Sorsa T. Levels and molecular forms of MMP-7 (matrilysin-1) and MMP-8 (collagenase-2) in diseased human peri-implant sulcular fluid. J Periodontal Res. 2003 Dec;38(6):583-90. [Medline: 14632921] [doi: 10.1034/j.1600-0765.2003.00688.x]

71. Bordin S, Flemmig TF, Verardi S. Role of fibroblast populations in peri-implantitis. Int J Oral Maxillofac Implants. 2009 Mar-Apr;24(2):197-204. [Medline: 19492634]

72. Irshad M, Scheres N, Anssari Moin D, Crielaard W, Loos BG, Wismeijer D, Laine ML. Cytokine and matrix metalloproteinase expression in fibroblasts from peri-implantitis lesions in response to viable Porphyromonas gingivalis. J Periodontal Res. 2013 Oct;48(5):647-56. [Medline: 23441812] [doi: 10.1111/jre.12051]

73. Hienz SA, Paliwal S, Ivanovski S. Mechanisms of Bone Resorption in Periodontitis. J Immunol Res. 2015;2015:615486. [Medline: 26065002] [PMC free article: 4433701] [doi: 10.1155/2015/615486]

\section{To cite this article:}

Fernandes MH, Gomes PS.

Bone Cells Dynamics during Peri-Implantitis: a Theoretical Analysis

J Oral Maxillofac Res 2016;7(3):e6

URL: http://www.ejomr.org/JOMR/archives/2016/3/e6/v7n3e6.pdf

doi: $10.5037 /$ jomr.2016.7306

Copyright (C) Fernandes MH, Gomes PS. Published in the JOURNAL OF ORAL \& MAXILLOFACIAL RESEARCH (http://www.ejomr.org), 9 September 2016.

This is an open-access article, first published in the JOURNAL OF ORAL \& MAXILLOFACIAL RESEARCH, distributed under the terms of the Creative Commons Attribution-Noncommercial-No Derivative Works 3.0 Unported License, which permits unrestricted non-commercial use, distribution, and reproduction in any medium, provided the original work and is properly cited. The copyright, license information and link to the original publication on (http://www.ejomr.org) must be included. 